\title{
Systemic sclerosis: correlation between lung abnormalities on high-resolution computed tomography (HRCT) and pulmonary function tests (PFTs)
}

\author{
Iman Mohamed Hamdy Ibrahim, Sherif Mohamed Gamal, Adham Mamdouh Salama and
}

Mostafa Ahmed Khairy* (1)

\begin{abstract}
Background: Systemic sclerosis is a connective tissue disease that affects multiple systems and causes fibrosis of the skin and internal organs. There are two ways in which the lungs can be involved in patients with systemic sclerosis, either isolated pulmonary hypertension or interstitial lung fibrosis. The purpose of this study is to correlate the high resolution $\mathrm{CT}$ findings with pulmonary function tests in patients with systemic sclerosis to evaluate the severity of lung changes.
\end{abstract}

Results: Significant inverse correlations were found between the maximal extent radiological score, maximal severity radiological score as well as total (global) radiological score on one hand and the pulmonary function tests on the other hand

Conclusion: The combination of high resolution $\mathrm{CT}$ and pulmonary function tests are recommended for better assessment of the extent and severity of systemic sclerosis associated interstitial lung disease.

Keywords: Systemic sclerosis, High-resolution CT, Pulmonary function tests, Interstitial lung disease, Pulmonary hypertension

\section{Background}

Systemic sclerosis (SSc) is a connective tissue disease that affects multiple systems and causes fibrosis of the skin and internal organs. Its etiology till now is unknown. This disease causes widespread damage to small and large blood vessels [1].

There are two ways in which the lungs can be involved in patients with systemic sclerosis, either isolated pulmonary hypertension or interstitial lung fibrosis. Lung affection is common and is probably the main cause of mortality in scleroderma patients [1].

Interstitial lung disease in systemic sclerosis (SSc) patients is common in both forms of the disease (diffuse

\footnotetext{
* Correspondence: Mostafakhairy11@gmail.com
}

Faculty of Medicine, Cairo University, Cairo, Egypt cutaneous and limited cutaneous). The disease is diagnosed at an advanced stage most of the time and this is probably due to the insidious onset of the disease accompanied by subtle clinical symptoms; at that point, the lung has become extensively fibrosed [2].

High-resolution computed tomography (HRCT) plays a major part in diagnosing interstitial lung disease in SSc patients. Its benefit lies more in assessing the extent of the disease [3].

Generally non-specific interstitial pneumonia (NSIP) is the commonest pattern detected in systemic sclerosis patients with more ground glass opacities than coarse reticulation detected. Usual interstitial pneumonia (UIP) can also be present $[4,5]$.

In clinical practice, pulmonary function tests (PFTs) are vital for assessing interstitial lung disease in 
Table 1 The American College of Rheumatology/European League against Rheumatism criteria for the classification of systemic sclerosis

\begin{tabular}{|c|c|c|}
\hline \multicolumn{3}{|c|}{2013 ACR / EULAR Criteria For The Classification Of Systemic Sclerosis (Scleroderma) ${ }^{\star}$} \\
\hline Item & Sub-items(s) & Weight/score ${ }^{+}$ \\
\hline $\begin{array}{l}\text { Skin thickening of the fingers of both hands extending proximal } \\
\text { to the metacarpophalangeal joints (sufficient criterion) }\end{array}$ & - & 9 \\
\hline Skin thickening of the fingers (only count the higher score) & $\begin{array}{l}\text { Putty fingers } \\
\text { Sclerodactyly of the fingers (distal to the metacarpophalangeal joints } \\
\text { but proximal to the proximal interphalangeal joints) }\end{array}$ & 4 \\
\hline Fingertip lesions (only count the higher score) & $\begin{array}{l}\text { Digital tip ulcers } \\
\text { Fingertip pitting scars }\end{array}$ & 2 \\
\hline Telangiectasia & - & 2 \\
\hline Abnormal nailfold capillaries & - & 2 \\
\hline $\begin{array}{l}\text { Pulmonary arterial hypertension and/or interstitial lung disease } \\
\text { (moximum score is 2) }\end{array}$ & $\begin{array}{l}\text { Pulmonary arterial hypertension } \\
\text { Interstitial lung disease }\end{array}$ & 2 \\
\hline Raynaud's phenomenon & - & 3 \\
\hline $\begin{array}{l}\text { SSc-related autoantibodies (anticentromere, } \\
\text { anti-topoisomerase I [anti-Scl-70], anti-RNA polymerase III] } \\
\text { (moximum score is 3) }\end{array}$ & $\begin{array}{l}\text { Anticentromere } 3 \\
\text { Anti-topoisomerase I } \\
\text { Anti-RNA polymerase III }\end{array}$ & 3 \\
\hline \multicolumn{3}{|c|}{$\begin{array}{l}\text { * The criteria are not applicable to patients with skin thickening sparing the fingers or to patients who have a scleroderma-like disorder that better explains } \\
\text { their manifestations (e.g., nephrogenic sclerosing fibrosis, generalized morphea, eosinophilic fasciitis, scleredema diabeticorum, scleromyxedema, } \\
\text { erythromyalgia, porphyria, lichen sclerosis, graft-versus-host disease, diabetic cheiroarthropathy). }\end{array}$} \\
\hline \multicolumn{3}{|c|}{$\begin{array}{l}\dagger \text { The total score is determined by adding the maximum weight (score) in each category. } \\
\text { Patients with a total score of } \geq 9 \text { are classified as having definite scleroderma. }\end{array}$} \\
\hline & Specificity $92 \%$ & \\
\hline
\end{tabular}

scleroderma patients. Forced vital capacity is considered a core outcome measure. However, they are not without limitations [2].

Patients with abnormal pulmonary function tests (spirometry) results may show normal high-resolution computed tomography findings [5].

Over the span of the past two decades, various systems for examining and quantifying interstitial lung disease in systemic sclerosis have been developed. Scoring methods utilize clinical information to characterize and quantify the disease, determine the progression of the disease and its response to therapy. (One of these methods uses semi-quantitative scoring which is developed in order to supply a more accurate assessment regarding interstitial lung disease abnormalities $[1,6]$.

\section{Aim of the work}

The aim of this study is to correlate the HRCT findings with pulmonary function tests in patients with systemic sclerosis to evaluate the severity of lung changes.

\section{Methods}

Thirty patients diagnosed with progressive systemic sclerosis were enrolled in this cross-sectional study during the period from October 2017 to December 2018.
The diagnosis has been established according to the 2013 American College of Rheumatology (ACR) classification criteria for SSC [7] (Table 1).

They were referred to the radiology department to do HRCT from the rheumatology, chest, internal medicine, and dermatology departments, as well as, the outpatient clinic of rheumatology.

Patients were also sent to the pulmonary function unit-chest department to do pulmonary function tests.

Table 2 Semi-quantitative scoring method: Warrick et al. [6]

\begin{tabular}{|c|c|c|c|}
\hline \multicolumn{2}{|l|}{ Severity score } & \multicolumn{2}{|l|}{ Extent score } \\
\hline Abnormality & Grading & $\begin{array}{l}\text { Bronchopulmonary segments for } \\
\text { each of the abnormality, score by } \\
\text { number of segments involved }\end{array}$ & Grading \\
\hline $\begin{array}{l}\text { Ground Glass } \\
\text { Opacities }\end{array}$ & 1 & 1 to 3 segments involved & 1 \\
\hline $\begin{array}{l}\text { Irregular Pleural } \\
\text { Margins }\end{array}$ & 2 & 4 to 9 segments involved & 2 \\
\hline $\begin{array}{l}\text { Septal or } \\
\text { Subpleural Lines }\end{array}$ & 3 & $>9$ segments involved & 3 \\
\hline Honeycombing & 4 & \multirow{2}{*}{$\begin{array}{l}\text { N.B. extent of disease } \\
\text { measured for each of } \\
\text { the abnormalities. }\end{array}$} & \\
\hline Subpleural Cyst & 5 & & \\
\hline $\begin{array}{l}\text { Maximal } \\
\text { severity score }\end{array}$ & 15 & Maximal extent score & 15 \\
\hline
\end{tabular}




\section{Inclusion criteria}

- Patients diagnosed with SSc older than 18 years regardless the gender presenting with chest symptoms and/or previous radiological findings suggestive of interstitial lung affection.

\section{Exclusion criteria}

- Smokers.

- Patients with mixed connective tissue diseases (MCTD).

- Patients unable to hold full inspiration during the exam.

\section{Clinical assessment}

- Full history taking

- General and chest clinical examination

- Routine laboratory investigations and sputum analysis when needed.

\section{HRCT}

The scans were performed using a Somatom, Emotion Siemens, 16-MDCT scanner.
Table 3 Different symptoms and signs in systemic sclerosis cases in the study

\begin{tabular}{ll}
\hline Description & Number (\%) total = 30 \\
\hline Primary chest complaint & $29(96.7)$ \\
$\quad$ Dyspnea & \\
Secondary Symptoms and Signs & $29(96.7)$ \\
Skin Tightness & $28(93.4)$ \\
Dysphagia & $17(56.7)$ \\
Dry Cough & $17(56.7)$ \\
Raynaud's Phenomenon & $13(43.4)$ \\
Chest Pain & $13(43.4)$ \\
Weight Loss & $9(30)$ \\
Wheezes & $3(10)$ \\
\hline
\end{tabular}

Patients were scanned in supine position during full inspiration. No intravenous contrast administered.

The scout was taken in supine position, $130 \mathrm{kV}, 25$ $\mathrm{mA}$ during holding breath in full inspiration.

Scans were obtained during full inspiration in supine position using the following parameters; $130 \mathrm{kV}, 78$ mAs, $5 \mathrm{~mm}$ beam collimation, 1.25 pitch, 0 gantry tilt and the FOV depending on patient's size. Total exposure

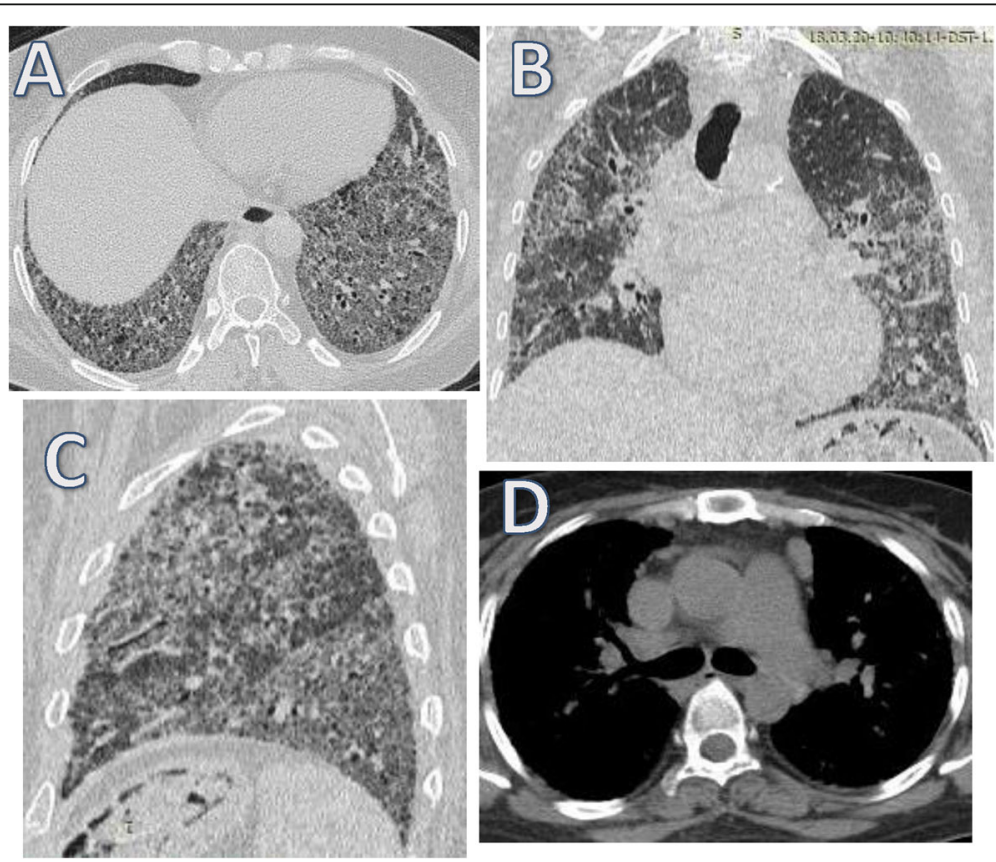

Fig. 1 A 43-year-old female patient presenting with progressive dyspnea. a-c Axial, coronal, and sagittal reformatted images of HRCT chest (lung window) showing interstitial lung disease in the form of bilateral fairly symmetrical predominantly subpleural ground glass opacification, thickening of interlobular and intralobular septae with traction bronchiectasis and bronchiolectasis and bilateral lower lobar reduced volume. Patulous esophagus is also noted on axial and coronal HRCT scans. $\mathbf{d}$ Axial mediastinal window showing prominent main pulmonary artery (about $3 \mathrm{~cm}$ ) and enlarged prevascular lymph nodes 

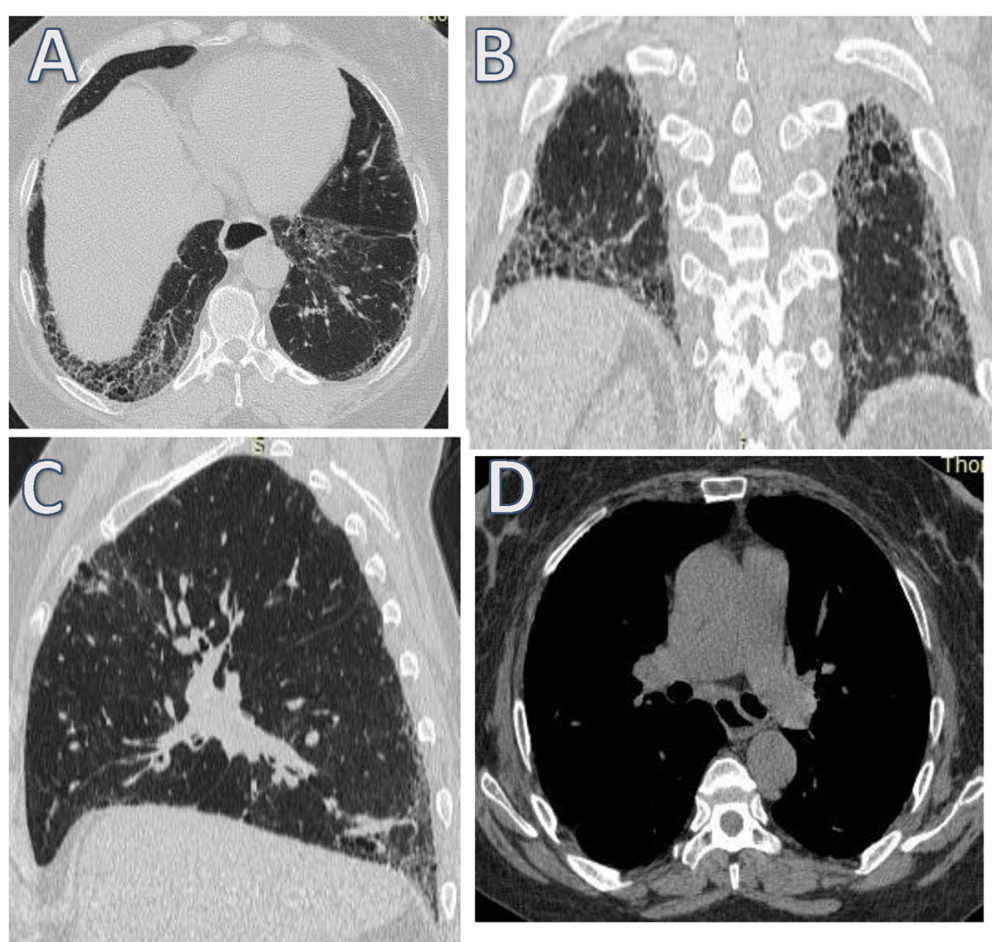

Fig. 2 A 43-year-old female patient presenting with progressive dyspnea. a-c Axial, coronal and sagittal reformatted images of HRCT chest (lung window) showing bilateral fairly symmetrical predominantly basal and subpleural ground glass opacification, thickening of interlobular, and intralobular septae with traction bronchiectasis and bronchiolectasis mounting to honeycombing. $\mathbf{d}$ Axial mediastinal window showing prominent main pulmonary artery and patulous esophagus showing air fluid level; findings impressive of interstitial lung disease (ILD) in the form of usual interstitial pneumonia (UIP)
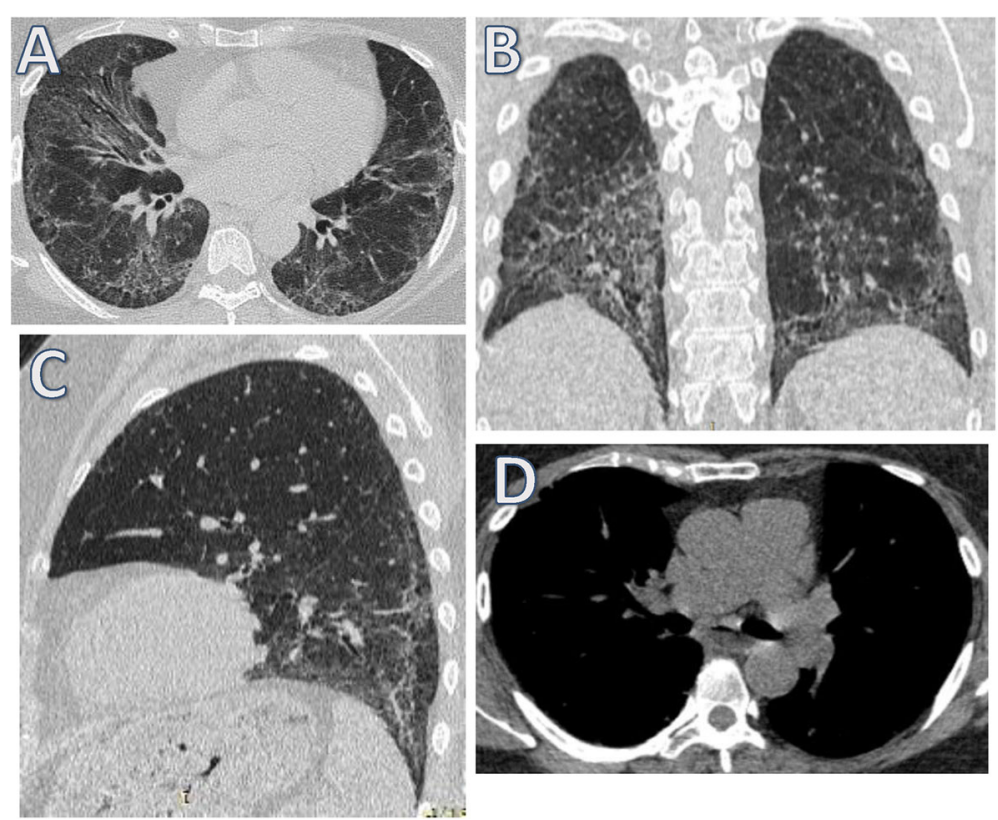

Fig. 3 A 46-year-old female patient diagnosed with systemic sclerosis presenting with progressive dyspnea. a-c Axial, coronal and sagittal reformatted images of HRCT chest (lung window) showing bilateral fairly symmetrical predominantly subpleural with relative sparing of direct subpleural region ground glass opacification, thickening of interlobular and intralobular septae, traction bronchiectasis and bronchiolectasis, and bilateral lower lobar reduced volume. $\mathbf{d}$ Axial mediastinal window showing dilated main pulmonary artery denoting pulmonary hypertension and patulous esophagus showing air fluid level; findings impressive of interstitial lung disease (ILD) in the form of non-specific interstitial pneumonia (NSIP) 

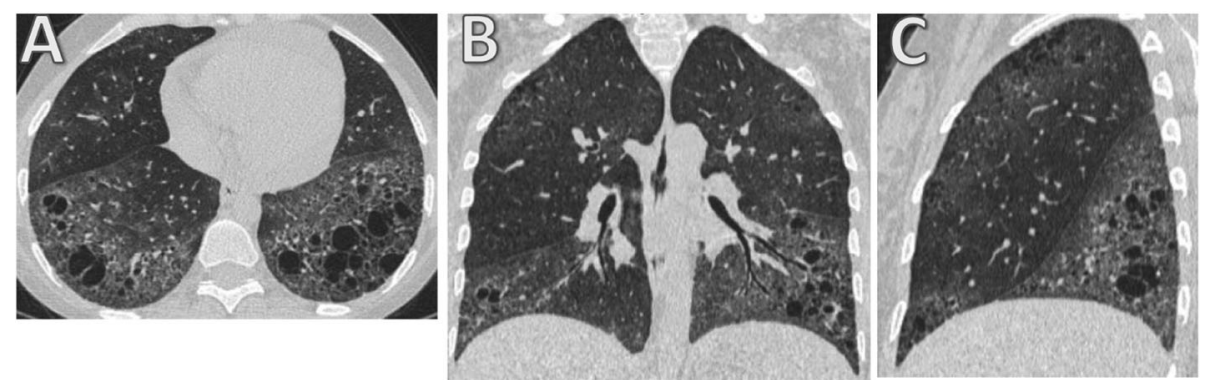

Fig. 4 A 22-year-old female patient diagnosed with systemic sclerosis presenting with progressive dyspnea. a-c Axial, coronal and sagittal reformatted images of HRCT chest (lung window) showing bilateral fairly symmetrical predominantly lower lobar and subpleural ground glass opacities and subpleural reticulations with reduced volume of both lower lung lobes. Bilateral predominantly lower lobar variable sized cysts are noted; findings impressive of interstitial lung disease (ILD) in the form of lymphocytic interstitial pneumonia (LIP)

time was $8-10 \mathrm{~s}$. The scans covered the whole thorax from root of the neck to below diaphragm.

Following acquisition, the acquired images were transferred to dedicated post-processing workstation and volumetric measurements were obtained by applying the multiplanar reformation function at slice thickness of 5 $\mathrm{mm}$.

Complementary mediastinal images were taken.

\section{Scoring parameters}

The scans were examined by 3 radiologists of 20, 10 , and 3 years of experience. The reported parenchymal findings were documented and coded. Each patient was given a maximal extent, maximal severity and global scores guided by Warrick's semi-quantitative scoring method used by Warrick et al. [6], Orlandi l et al. [8], Afeltra et al. [9], Camiciottoli et al. [10], Yiannopoulos et al .[11], Bellia et al. [12], Savarino et al. [13], and Daoussis D et al. [14] (Table 2).

Warrick's semi-quantitative scoring method depends on 5 HRCT abnormalities; ground-glass opacities, irregular pleural margin, septal or subpleural lines, honeycombing, and subpleural cyst.

Concerning the severity, it depends on the mere presence of abnormalities regardless of how many bronchopulmonary segments. Each finding was assigned a grade then they were added to get a maximal severity score. The highest score that can be assigned to one case is 15 if all abnormalities are present.

While the extent score is calculated according to the total number of bronchopulmonary segments involved by each abnormality. The maximal extent score is calculated by adding the grade for each abnormality with maximal score of 15 if every abnormality is present in more than 9 bronchopulmonary segments.

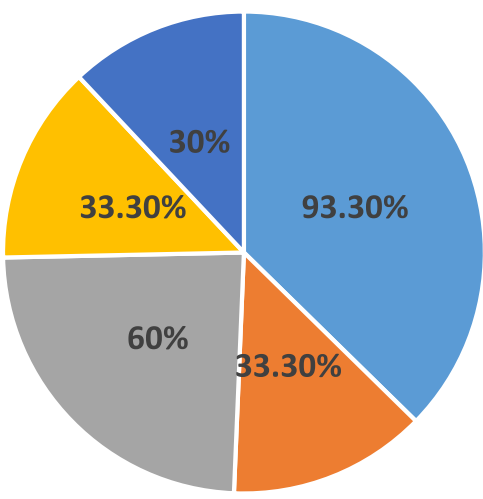

\section{- Ground Glass Opacification \\ - Septal / Subpleural Lines \\ - Subpleural Cyst}

- Irregular Pleural Margins

- Honeycombing

Fig. 5 Chart demonstrating the percentage of the semi-quantitative scoring system related fibrotic abnormalities among the systemic sclerosis cases in the study 
Table 4 Description of extent and severity score findings

\begin{tabular}{lllll}
\hline HRCT findings & \multicolumn{2}{l}{ Description Number (\%) total $=30$} & $\begin{array}{l}\text { 4-9 segments } \\
\text { (score 2) }\end{array}$ & $\begin{array}{c}\text { >9 segments } \\
\text { (score 3) }\end{array}$ \\
\cline { 2 - 5 } & Mere presence & (score 1) & $8(26.7)$ & $17(56.7)$ \\
\hline Ground glass (1) & 28 & $3(10)$ & $3(10)$ & $2(6.7)$ \\
Irregular Pleural Margins (2) & 10 & $5(16.7)$ & $4(13.3)$ & $9(30)$ \\
Septal / Subpleural Lines (3) & 19 & $5(16.7)$ & $3(10)$ & $4(13.3)$ \\
Honeycombing (4) & 10 & $3(10)$ & $1(3.3)$ & $0(0)$ \\
Subpleural Cyst (5) & 9 & $8(26.7)$ & &
\end{tabular}

Both scores combined to obtain the global score.

The global score $=$ maximal severity score + maximal extent score. The maximum score for any case is 30 .

\section{Pulmonary function tests}

All patients performed PFTs using Master Screen PFT pro Care fusion Germany $234 \mathrm{GmbH}$ in the pulmonary function unit-Chest Department.

Each patient performed a standard forced vital capacity maneuver (FVC), inspiring fully to total lung capacity (TLC), then exhaling as rapidly and forcibly as possible to residual volume (RV) and to complete the loop. Then, he/she inspires as rapidly as possible from the maximal expiratory level back to maximal inspiration.

Volume is plotted on the horizontal $X$ axis, and flow is plotted on the vertical $Y$ axis [15].

\section{Statistical methods and data analysis}

Data was entered on the computer using "Microsoft Office Excel Software" program (2010) for windows.

Data was then transferred to the Statistical Package of Social Science Software program, version 23 (IBM SPSS Statistics for Windows, Version 23.0. Armonk, NY: IBM Corp.) to be statistically analyzed.

Data presented using range, mean, standard deviation, median and interquartile range for quantitative variables and frequency and percentage for qualitative ones.

Pearson correlation coefficients calculated to assess the association between extent, severity and global scores with different pulmonary functions. $\mathrm{P}$ values less than 0.05 were considered statistically significant. Figures were used to illustrate some information.

\section{Results}

Thirty patients diagnosed with systemic sclerosis were included in our study; 28 females and 2 males. Their age range from 22 to 60 years old with mean age of $41.4 \pm$ 11 SD.

All patients had clinical symptoms suggestive of interstitial lung disease. Dyspnea was the primary chest complaint seen in $96.7 \%$ of cases (Table 3).

\section{HRCT findings}

Warrick's semi-quantitative scoring method depends on 5 HRCT abnormalities; ground-glass opacities, irregular pleural margin, septal or subpleural lines, honeycombing and subpleural cysts (Figs. 1, 2, 3, and 4).

Global score guided by Warrick scoring system: 28

Global score guided by Warrick scoring system: 27

Global score guided by Warrick scoring system: 26

Global score guided by Warrick scoring system: 25

HRCT fibrotic parenchymal abnormalities considered in the semi-quantitative method of Warrick's scoring system are demonstrated in chart (Fig. 5). Ground-glass opacification was the most common findings seen in $93.3 \%$ of the cases followed by septal/subpleural lines seen in $60 \%$ of cases.

After analyzing the HRCT images guided by the semiquantitative method of Warrick's scoring system, maximal extent, maximal severity, and maximal global scores of fibrosis were calculated for each patient (Tables 4 and 5).

Results of the extent and severity of ILD showed that ground glass opacification is the most common finding in our patients with $56 \%$ of patients showing more than 9 bronchopulmonary segments involvement ( score 3), followed by septal-subpleural lines with $30 \%$ of patients showing (score 3).

The total Warrick score of the patients involved in our study was $11.5 \pm 8.1$ [mean \pm standard deviation (SD)]

$S D$ standard deviation, $I Q R$ interquartile range (range between 25th and 75th percentiles)

Table 5 Description of Score findings (range, mean, and median)

\begin{tabular}{llll}
\hline HRCT findings & \multicolumn{3}{l}{ Description $(n=30)$} \\
\cline { 2 - 4 } & Range & Mean \pm SD & Median (IQR) \\
\hline Ground glass (1) & $0-3$ & $2.3 \pm 0.9$ & $3(2-3)$ \\
Irregular Pleural Margins (2) & $0-3$ & $0.6 \pm 0.9$ & $0(0-1)$ \\
Septal / Subpleural Lines (3) & $0-3$ & $1.3 \pm 1.3$ & $1(0-3)$ \\
Honeycombing (4) & $0-3$ & $0.7 \pm 1.1$ & $0(0-1.3)$ \\
Subpleural Cyst (5) & $0-2$ & $0.3 \pm 0.5$ & $0(0-1)$ \\
Maximal Extent Score & $0-13$ & $5.3 \pm 3.5$ & $5(3-7)$ \\
Maximal Severity Score & $0-15$ & $6.2 \pm 4.9$ & $6(1-9)$ \\
Global Score & $0-28$ & $11.5 \pm 8.1$ & $10(4-15)$ \\
\hline
\end{tabular}


Table 6 Different patterns of ILD

\begin{tabular}{lll}
\hline $\begin{array}{l}\text { Interstitial lung disease (ILD) } \\
\text { Non-specific interstitial } \\
\text { pneumonia (NSIP) }\end{array}$ & $\begin{array}{l}\text { Usual interstitial } \\
\text { pneumonia (UIP) }\end{array}$ & $\begin{array}{l}\text { Lymphoid interstitial } \\
\text { pneumonia (LIP) }\end{array}$ \\
\hline $13(65 \%)$ & $5(25 \%)$ & $2(10 \%)$ \\
\hline
\end{tabular}

Different forms of interstitial lung disease (ILD) were detected in twenty patients (66.6\%). Numbers and percentages of different types of ILD are shown in Table 6.

Other findings in the HRCT scans are demonstrated in chart (Fig. 6).

Dilated pulmonary artery $(2.9 \mathrm{~cm}$ or more) was noted in $40 \%$ of patients suggesting the possibility of pulmonary arterial hypertension.

\section{Pulmonary function tests (PFTs) findings}

All patients underwent pulmonary function testing (spirometry), with emphasis on forced vital capacity (FVC), forced expiratory volume in $1 \mathrm{~s}$ (FEV1) and FEV1\%FVC (Table 7).

According to PFT (spirometry) values, the majority of the patients in the study showed mild restriction (36.7\%) and moderate restriction (36.7\%) equally (Fig. 7), while $33.3 \%$ of patients showed airway obstruction (mild, moderate or severe (Fig. 8).

\section{Correlations between HRCT scores and PFTs}

Maximum extent, severity, and global scores for all patients were correlated with spirometry results and demonstrated in (Tables 8, 9, and 10) (Figs. 9, 10, and 11).

Significant inverse correlations were found between the maximal extent radiological score and lung-function (spirometry) parameters [predicted FVC: $r=-0.540, p=$ 0.002; predicted forced expiratory volume in $1 \mathrm{~s}$ (FEV1): $r$ $=-0.525, p=0.003$; best forced expiratory volume in $1 \mathrm{~s}$ (FEV1): $r=-0.430, p=0.018$ (Table 8, Fig. 9).
Table 7 Description of PFTs (spirometry)

\begin{tabular}{lll}
\hline & \multicolumn{2}{l}{ Description $(n=30)$} \\
\cline { 2 - 3 } & Range & Median (IQR) \\
\hline Pred (FVC) & $2.2-5$ & $3.2(2.8-3.4)$ \\
\% (B/P) (FVC) & $28.8-101.8$ & $63.7(51-77.6)$ \\
Pred (FEV1) & $1.8-4.2$ & $2.8(2.4-3)$ \\
Best (FEV1) & $0.6-3.7$ & $1.7(1.3-2)$ \\
\% (B/P) (FEV1) & $30.1-94$ & $65.4(48.5-75.6)$ \\
Pred (FEV1 \% FVC) & $78.1-88.3$ & $85.9(84.7-87.2)$ \\
Best (FEV1 \% FVC) & $37.1-100$ & $83.8(79.6-91.3)$ \\
\% (B/P) (FEV1 \% FVC) & $43-128$ & $97.5(93-105)$ \\
\hline
\end{tabular}

IQR interquartile range (range between 25 th and 75 th percentiles)

There was no significant correlation between the maximal extent score and the rest of the PFT (spirometry) parameters.

Significant inverse correlations were found between the maximal severity radiological score and lungfunction (spirometry) parameters [predicted FVC: $r=-$ $0.421, p=0.020$; predicted forced expiratory volume in 1 s (FEV1): $r=-0.398, p=0.029$; best FEV1 \% FVC: $r=$ $-0.366, p=0.046$; percentage $\mathrm{B} / \mathrm{P}$ of FEV1 \% FVC: $r=$ $-0.373, p=0.042$ (Table 9, Fig. 10).

There was no significant correlation between the maximal severity score and the rest of the PFT (spirometry) parameters.

Significant inverse correlations were found between the total (global) radiological score and lung-function (spirometry) parameters [predicted FVC: $r=-0.486, p$ $=0.006$; predicted forced expiratory volume in $1 \mathrm{~s}$ (FEV1): $r=-0.466, p=0.009$; best of (FEV1 \% FVC): $r$ $=-0.364, p=0.048$; percentage $\mathrm{B} / \mathrm{P}$ of FEV1\%FVC: $r=$ - 0.368, p=0.045 (Table 10, Fig. 11).

There was no significant correlation between the global score and the rest of the PFT (spirometry) parameters.
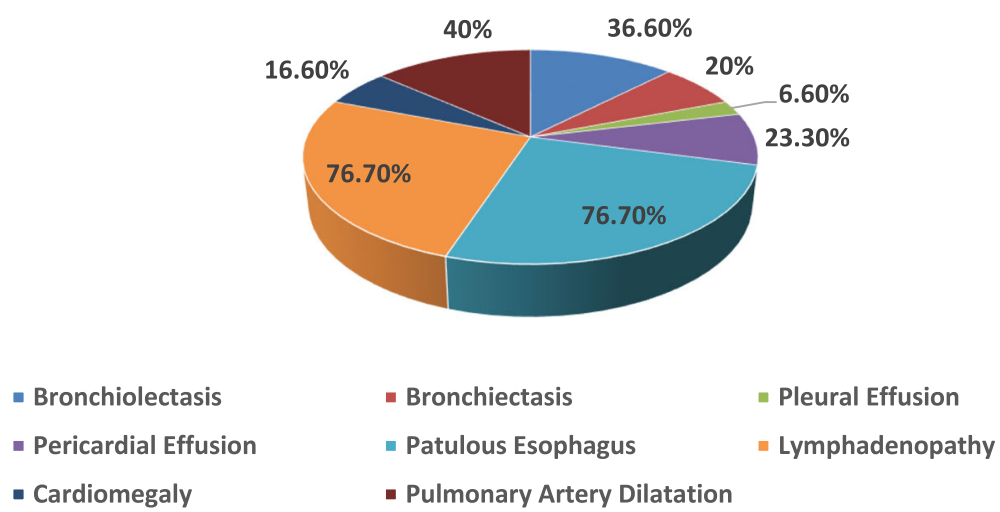

Fig. 6 Chart showing other finding in HRCT scans 


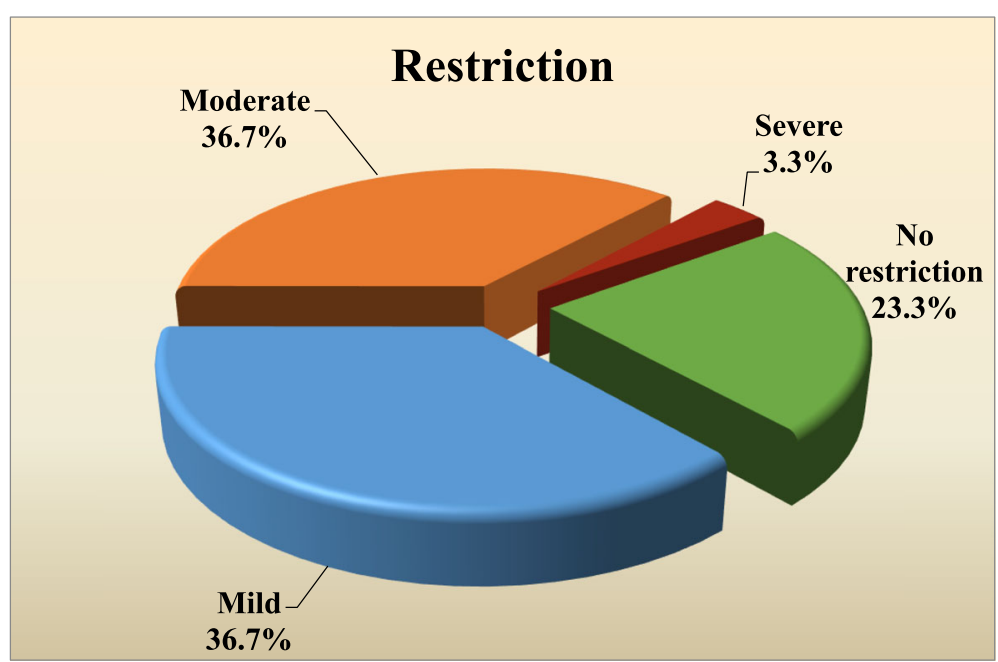

Fig. 7 Percentage of restriction in systemic sclerosis patients in the study according to spirometry values

\section{Discussion}

Systemic sclerosis (SSc) is a connective tissue disease affecting multiple organs within the human body, especially the lungs. It is defined by dysfunction of the endothelium of blood vessels leading to vasculopathy of small vessels and a disturbance in the fibroblastic function ending in exaggerated collagen formation and fibrosis of the skin and internal organs [16].

The commonest causes of morbidity and mortality in patients suffering from SSc are interstitial lung disease (ILD) and pulmonary hypertension [4, 17]. ILD is a frequent pulmonary manifestation of SSc [18]. Roughly forty percent of patients suffering from SSc have some degree of ILD [19].

This study involved reviewing the HRCT scans of 30 patients which were referred to radiology department kasr Al-Aini due to their chronic chest complaint. All patients were known cases of SSc presenting with dyspnea and cough.

This study involved 30 patients; 28 females and 2 males which were in agreement with the study done by Bellia et al. [12] that involved 31 patients; 30 females and 1 male.

Twenty patients in our study (66.6\%) manifest some form of ILD which is consistent with Tardella et al. [20]. Different forms of ILD were detected in the form of either NSIP in $13(65 \%)$ of the patients, UIP $5(25 \%)$ of patients, and 2 patients (10\%) had ILD in the form of lymphocytic interstitial pneumonitis (LIP) which were very close to the results produced by Wells [21], stating that NSIP was found in 78\%, UIP was found in $8 \%$ of the patients and also in agreement with the study done by Zompatori et al. [22] where 14 out 16 cases with ILD

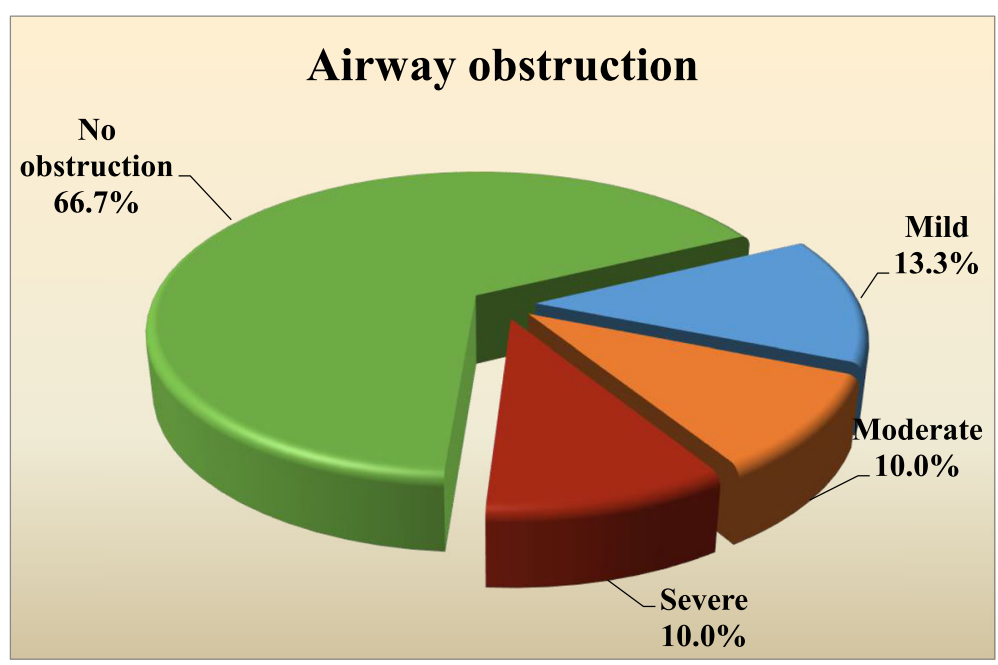

Fig. 8 Percentage of airway obstruction in systemic sclerosis patients in the study according to spirometry values 
Table 8 Correlation of maximal extent score with pulmonary function (spirometry)

\begin{tabular}{|c|c|c|}
\hline & Maximal & \\
\hline & $r$ & $P$ value \\
\hline Pred (FVC) & -0.540 & 0.002 \\
\hline Best (FVC) & -0.314 & 0.091 \\
\hline$\%(\mathrm{~B} / \mathrm{P})(\mathrm{FVC})$ & 0.049 & 0.799 \\
\hline Pred (FEV1) & -0.525 & 0.003 \\
\hline Best (FEV1) & -0.430 & 0.018 \\
\hline$\%(\mathrm{~B} / \mathrm{P})$ (FEV1) & -0.168 & 0.375 \\
\hline Pred (FEV1 \% FVC) & -0.120 & 0.529 \\
\hline Best (FEV1 \% FVC) & -0.332 & 0.073 \\
\hline$\%(B / P)(F E V 1 \%$ FVC) & -0.331 & 0.074 \\
\hline
\end{tabular}

$r$ Pearson correlation coefficient

Table 9 Correlation of maximal severity score with pulmonary functions (spirometry)

\begin{tabular}{|c|c|c|}
\hline & \multicolumn{2}{|c|}{ Maximal severity score } \\
\hline & $r$ & $P$ value \\
\hline Pred (FVC) & -0.421 & 0.020 \\
\hline Best (FVC) & -0.154 & 0.417 \\
\hline$\%(\mathrm{~B} / \mathrm{P})(\mathrm{FVC})$ & 0.168 & 0.375 \\
\hline Pred (FEV1) & -0.398 & 0.029 \\
\hline Best (FEV1) & -0.287 & 0.125 \\
\hline$\%(B / P)(F E V 1)$ & -0.059 & 0.758 \\
\hline Pred (FEV1 \% FVC) & 0.002 & 0.993 \\
\hline Best (FEV1 \% FVC) & -0.366 & 0.046 \\
\hline$\%(B / P)(F E V 1 \%$ FVC) & -0.373 & 0.042 \\
\hline
\end{tabular}

$r$ Pearson correlation coefficient

Table 10 Correlation of global score with pulmonary functions (spirometry)

\begin{tabular}{lll}
\hline & Global score & $P$ value \\
\cline { 2 - 3 } & $r$ & $\mathbf{0 . 0 0 6}$ \\
Pred (FVC) & -0.486 & 0.227 \\
Best (FVC) & -0.227 & 0.518 \\
\% (B/P) (FVC) & 0.123 & $\mathbf{0 . 0 0 9}$ \\
Pred (FEV1) & $-\mathbf{0 . 4 6 6}$ & 0.052 \\
Best (FEV1) & -0.357 & 0.572 \\
\% (B/P) (FEV1) & -0.107 & 0.793 \\
Pred (FEV1 \% FVC) & -0.050 & $\mathbf{0 . 0 4 8}$ \\
Best (FEV1 \% FVC) & $-\mathbf{0 . 3 6 4}$ & $\mathbf{0 . 0 4 5}$ \\
\% (B/P) (FEV1 \% FVC) & $\mathbf{- 0 . 3 6 8}$ & \\
\hline
\end{tabular}

$r$ Pearson correlation coefficient 


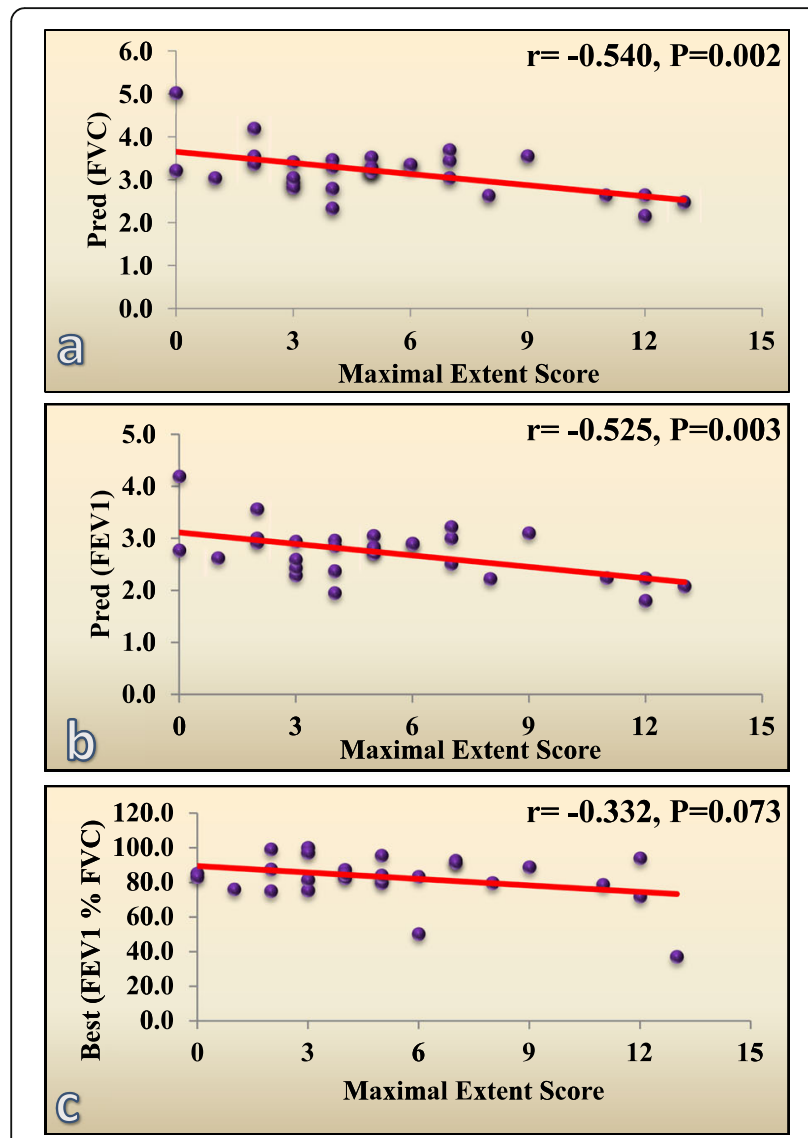

Fig. 9 a Correlation between maximal extent score and predicted (FVC). b Predicted (FEV1). c Best (FEV1\%FVC)

exhibited an NSIP pattern, while only 2 showed a UIP pattern; therefore, establishing NSIP as the commonest ILD pattern in SSc.

The most common abnormalities indicative of fibrosis reported on HRCT in this study were ground glass opacification (93.3\%) followed by septal/subpleural lines (60\%), honeycombing (33.3\%), irregular pleural margins (33.3\%), and subpleural cysts (30\%). These results are close to the study done by Hafez et al. [23] which showed ground glass opacification in $(83.3 \%)$ followed by septal/subpleural lines in $(56.7 \%)$, honeycombing in (43.3\%) bronchiolectasis in $(23.3 \%)$ of the patients. Our results were also in agreement with the study done by Shah et al. [24] which shows ground glass as the leading abnormality in SSc present in $66 \%$ of their patients. while a study done by De Oliveira Jezler et al. [25] yielded different results showing bronchiolectasis as the most common HRCT abnormality found in (83.3\%) of patients followed by honeycombing (80\%), ground-glass opacity (66.7\%), and septal/subpleural lines (20\%).

Bronchiolectasis was found in $11(36.6 \%)$ of the patients in our study which was not in agreement with the
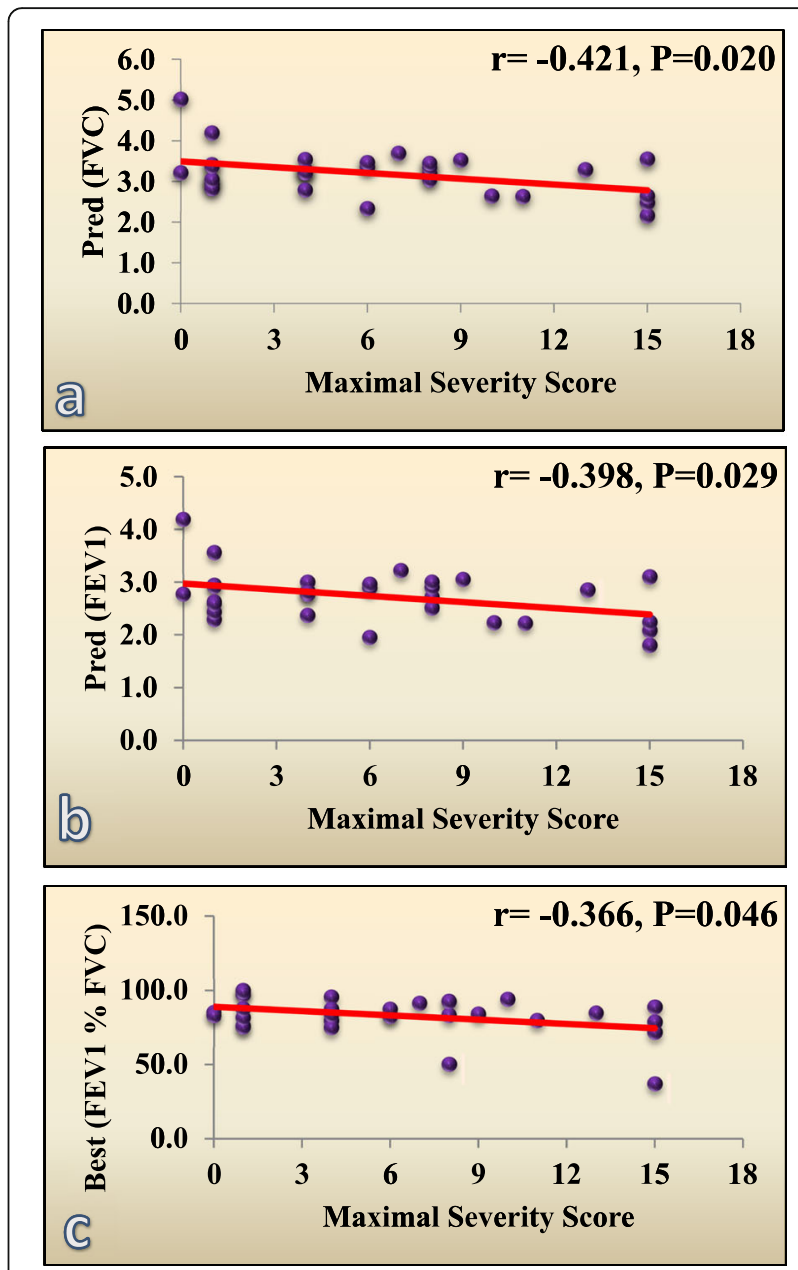

Fig. 10 a Correlation between maximal severity score and predicted (FVC). b Predicted (FEV1). c Best (FEV1\%FVC)

study done by Pontana et al. [26], as their study showed bronchiolectasis in 27 (49\%) of their patients. This could be due to the fact that their study involved more patients (55) than ours.

This study showed traction bronchiectasis in $6(20 \%)$ of the patients which was consistent with studies by Tillie-Leblond et al. [27] and by Burt et al. [28] being seen in $7(22 \%)$ out of 32 patients and in $7(10 \%)$ out of 90 patients, respectively. Although according to Ferguson et al. [29], traction bronchiectasis is considered to be one of the predominant abnormalities found on HRCT scans.

This study showed that 12 (40\%) of the patients exhibited a pulmonary artery diameter more than $2.9 \mathrm{~cm}$ on HRCT suggestive of pulmonary arterial hypertension which was in agreement with Capobianco et al. [30] who stated that $10(33 \%)$ of SSc patients had a dilated pulmonary artery. However, our study was not consistent with another study done by Zompatori et al. [22] which 

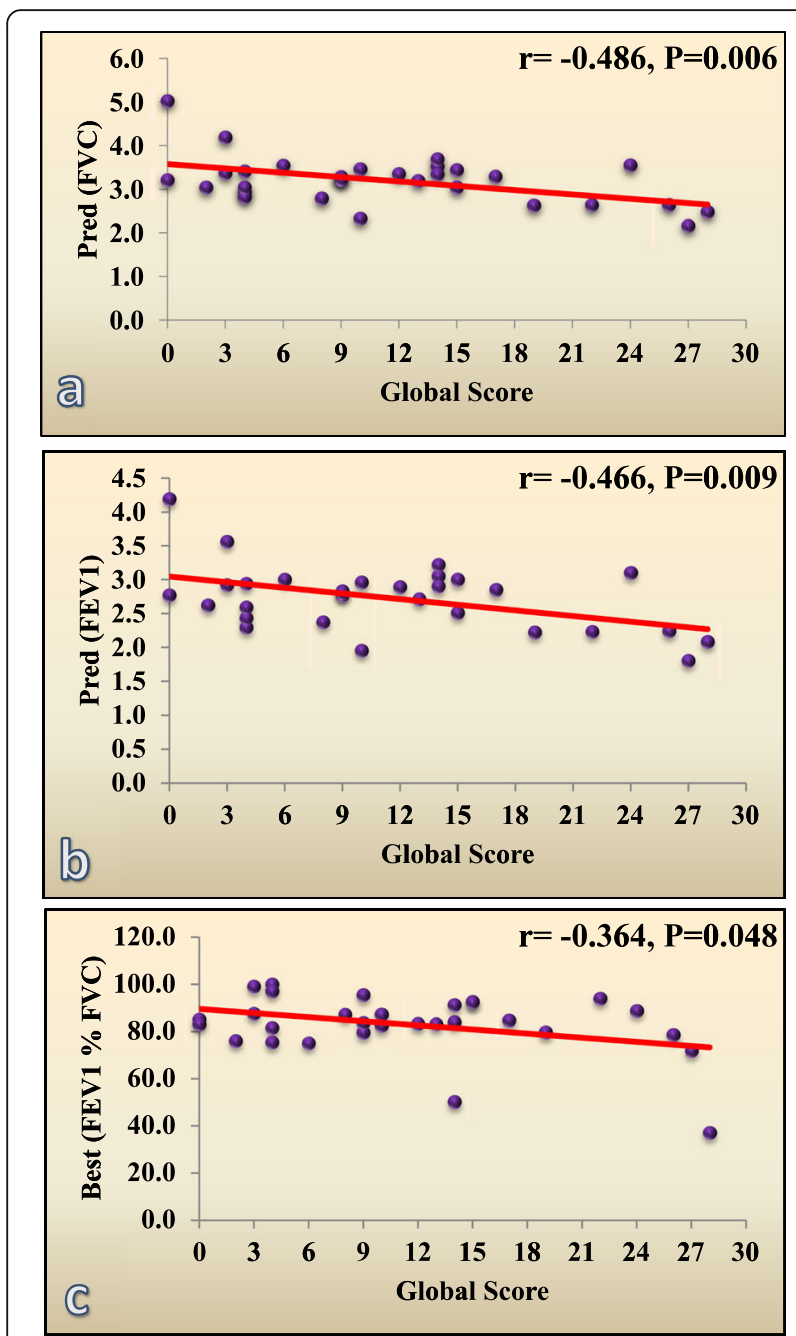

Fig. 11 a Correlation between global score and predicted (FVC). b Predicted (FEV1). c Best (FEV1\%FVC)

showed that 41 (95\%) of the studied patients exhibited a pulmonary artery diameter $>2.9 \mathrm{~cm}$. This dilatation could be considered primary as a result of pulmonary vascular abnormalities unrelated to SSc or it could be a secondary cause due to SSc-ILD.

Mediastinal lymph nodes were found in 23 (76.7\%) patients which was not consistent with the study done by Tumsatan et al. [31] that showed mediastinal lymphadenopathy in $56.7 \%$ of the patients and this could be due to the discrepancy in the number of patients.

This study showed 2 (6.6\%) patients with pleural effusion which agreed with the study done by Tillie-Leblond et al. [27] which showed that $3(9.3 \%)$ of patients showed pleural effusion. Also, 7 (23.3\%) of our patients showed pericardial effusion and this was close to the study done by Meune et al. [32] which showed pericardial effusion in $16(30 \%)$ of their patients.
Esophageal dilatation is commonly detected in individuals with SSc on HRCT scans. It was stated by Leipsic et al. [33] that a patulous esophagus is often observed in 58 to $80 \%$ of individuals suffering from SSc and that this finding suggests a diagnosis of SSc. This was consistent with our study which revealed dilated esophagus in $76.7 \%$ of patients.

This study was done to determine the importance of HRCT in diagnosing and defining the type and degree of anatomical destruction brought on by systemic sclerosis. To determine the degree of lung fibrosis caused by SSc, the Warrick semi-quantitative scoring system was utilized.

A significant inverse correlation of moderate strength between the Warrick score and predicted FEV1 $(r=-$ 0.466, $p=0.009$ ) was shown being consistent with the study done by Bellia et al. [12] which showed $(r=-$ 0.36, $p=0.05)$ and Ooi et al. [34] which showed $(r=-$ $0.43, p=0.008$ ), also with the study done by Zompatori et al. [22] which showed $p=0.01$.

This study showed also a significant inverse correlation of moderate strength between the Warrick score and FVC $(r=-0.486, p=0.006)$ which was similar to the study done by Ooi et al. [34] which yielded results in the form of $(r=-0.43, p=0.008)$. Our results were also similar to the study done by Yilmaz et al. [17] which showed significant correlations between the Warrick score and FVC.

This study also showed a significant inverse correlation between the Warrick score and FEV1\%FVC ( $r=-$ $0.36, p=0.048$ ); however, there are no available studies to corroborate these findings.

In this study, there was no significant correlation between the Warrick score (global score) and FVC\%; however, a study done by Cakmak et al. [1] yielded different results, as they managed to establish a negative correlation between the Warrick score and FVC\% $(r=-0.28$, $p=0.026)$. This could be due to the smaller number of patients in our study in comparison to theirs.

We were not able to correlate the rest of the pulmonary function components with the Warrick HRCT scoring system which includes TLC and DLCO in addition to the spirometry values present in our study due to limited availability regarding these particular tests at our institute.

\section{Conclusion}

This study showed a significant inverse correlation between the HRCT Warrick scoring system and spirometric indices (FVC, FEV1, and FEV1\%FVC).

The combination of HRCT and PFTs (spirometry) testing are recommended for better assessment of the extent and severity of SSc-ILD. 


\section{Abbreviations}

ACR: American College of Rheumatology; DLCO: Diffusing capacity of the lungs for carbon monoxide; FEV1: Forced expiratory volume in $1 \mathrm{~s}$; FOV: Field of view; FVC: Forced vital capacity; HRCT: High-resolution computed tomography; ILD: Interstitial lung disease; LIP: Lymphocytic interstitial pneumonitis; MDCT: Multidetector computed tomography; NSIP: Nonspecific interstitial pneumonia; PFTs: Pulmonary function tests; RV: Residual volume; SD: Standard deviation; SPSS: Statistical Package for the Social Science; SSc: Systemic sclerosis; TLC: Total lung capacity; UIP: Usual interstitial pneumonia

\section{Acknowledgements}

The authors would like to thank all the personnel contributed in this study.

\section{Authors' contributions}

IH shared in study conception and design, collected patients' data, processed $\mathrm{CT}$ findings at CT work station, and shared in writing and correcting the manuscript and revision. SM shared in study conception and design, clinical examination, acquisition of data, analysis and interpretation of data, and drafting of manuscript. AS shared in collecting patients' data, processing $\mathrm{CT}$ findings at $\mathrm{CT}$ work station, and shared in writing the manuscript. MK shared in study conception and design, acquisition of data, analysis and interpretation of data, and drafting of manuscript. All authors read and approved the final manuscript.

\section{Funding}

This study had no funding from any resource.

\section{Availability of data and materials}

The datasets used and/or analyzed during the study are available upon reasonable request.

\section{Ethics approval and consent to participate}

No individual data included in the study.

This study was approved by the Research Ethics Committee of the Faculty of Medicine at Cairo University Kasr El-Aini in Egypt in October 2017; reference number I-181017

All patients included in this study gave verbal informed consent to participate in this research.

\section{Consent for publication}

All patients included in this study gave written informed consent to publish the data contained within this study.

\section{Competing interests}

The authors declare that they have no competing interests.

Received: 30 March 2020 Accepted: 2 June 2020

Published online: 12 June 2020

\section{References}

1. Cakmak G, Can TS, Gundogdu S et al (2016) Relationship between abnormalities on high-resolution computerized tomography, pulmonary function, and bronchoalveolar lavage in progressive systemic sclerosis. Sarcoidosis Vasculitis and Diffuse Lung Disease 33(4):349-354

2. Hoffmann Vold AM, Aaløkken TM, Lund MB et al (2015) Predictive Value of Serial High-Resolution Computed Tomography Analyses and Concurrent Lung Function Tests in Systemic Sclerosis: SERIAL LUNG ANALYSES IN SSc. Arthritis \& Rheumatology 67(8):2205-2212

3. Wells, A.U. (2008). High-resolution computed tomography and scleroderma lung disease. Rheumatology, 47(Supplement 5), v59-v61.

4. Schoenfeld SR, Castelino FV (2015) Interstitial Lung Disease in Scleroderma. Rheumatic Disease Clinics of North America 41(2):237-248

5. Solomon, J.J., Olson, A.L., Fischer, A., et al (2013). Scleroderma lung disease.

6. Warrick JH, Bhalla M, Schabel SI et al (1991) High resolution computed tomography in early scleroderma lung disease. The Journal of rheumatology 18(10):1520-1528

7. Van Den Hoogen F, Khanna D, Fransen J et al (2013) 2013 Classification Criteria for Systemic Sclerosis: An American College of Rheumatology/ European League Against Rheumatism Collaborative Initiative: ACR/EULAR Classification Criteria for SSC. Arthritis \& Rheumatism 65(11):2737-2747
8. Orlandi I, Camiciottoli G, Diciotti S, Bartolucci M, Cavigli E et al (2006) Thinsection and low-dose volumetric computed tomographic densitometry of the lung in systemic sclerosis. J Comput Assist Tomogr 30:823-827

9. Afeltra A, Zennaro D, Garzia P, Gigante A, Vadacca M et al (2006) Prevalence of interstitial lung involvement in patients with connective tissue diseases assessed with high-resolution computed tomography. Scand J Rheumatol 35:388-394

10. Camiciottoli G, Orlandi I, Bartolucci M, Meoni E, Nacci F et al (2007) Lung CT densitometry in systemic sclerosis: correlation with lung function, exercise testing, and quality of life. Chest 131:672-681

11. Yiannopoulos G, Pastromas V, Antonopoulos I, Katsiberis G, Kalliolias G et al (2007) Combination of intravenous pulses of cyclophosphamide and methylprednizolone in patients with systemic sclerosis and interstitial lung disease. Rheumatol Int 27:357-361

12. Bellia M, Cannizzaro F, Scichilone N et al (2009) HRCT and scleroderma: semiquantitative evaluation of lung damage and functional abnormalities. La Radiologia Medica 114(2):190-203

13. Savarino E, Bazzica M, Zentilin P, Pohl D, Parodi A et al (2009) Gastroesophageal reflux and pulmonary fibrosis in scleroderma: a study using pH-impedance monitoring. Am J Respir Crit Care Med 179:408-413

14. Daoussis D, Liossis SN, Tsamandas AC, Kalogeropoulou C, Kazantzi A et al (2010) Experience with rituximab in scleroderma: results from a 1-year, proof of-principle study. Rheumatology (Oxford) 49:271-280

15. Miller MR (2005) Standardisation of spirometry. European Respiratory Journal 26(2):319-338

16. Asano Y (2018) Systemic sclerosis. The Journal of Dermatology 45(2):128-138

17. Yilmaz N, Can M, Kocakaya D et al (2014) Two-year experience with mycophenolate mofetil in patients with scleroderma lung disease: a case series. International Journal of Rheumatic Diseases 17(8):923-928

18. Takei R, Arita M, Kumagai S et al (2018) Radiographic fibrosis score predicts survival in systemic sclerosis-associated interstitial lung disease: Radiographic fibrosis in SSc-ILD. Respirology 23(4):385-391

19. Ueda T, Sakagami T, Kikuchi T et al (2018) Mycophenolate mofetil as a therapeutic agent for interstitial lung diseases in systemic sclerosis. Respiratory Investigation 56(1):14-20

20. Tardella M, Di Carlo M, Carotti M et al (2018) Ultrasound B-lines in the evaluation of interstitial lung disease in patients with systemic sclerosis: Cutoff point definition for the presence of significant pulmonary fibrosis. Medicine 97(18):e0566

21. Wells AU (2014) Interstitial lung disease in systemic sclerosis. La Presse Médicale 43(10):e329-e343

22. Zompatori M, Leone MB, Giannotta M et al (2013) Pulmonary hypertension and systemic sclerosis: the role of high-resolution computed tomography. La Radiologia Medica 118(8):1360-1372

23. Hafez EA, Hamza SH, Morad CS et al (2018) Pulmonary manifestations in Egyptian patients with systemic sclerosis. The Egyptian Rheumatologist 40(1):39-44

24. Shah RM, Jimenez S, Wechsler R (2007) Significance of ground-glass opacity on HRCT in long-term follow-up of patients with systemic sclerosis. Journal of Thoracic Imaging 22(2):120-124

25. De Oliveira Jezler, S.F., Santiago, M.B., Andrade, T.L., et al (2005). Vol 31-Ed 4page 300 to 306 (July August).

26. Pontana F, Billard AS, Duhamel A et al (2015) Effect of Iterative Reconstruction on the Detection of Systemic Sclerosis-related Interstitial Lung Disease: Clinical Experience in 55 Patients. Radiology 279(1):297-305

27. Tillie-Leblond I, Wislez M, Valeyre D et al (2008) Interstitial lung disease and anti-Jo-1 antibodies: difference between acute and gradual onset. Thorax 63(1):53-59

28. Burt RK, Oliveira MC, Shah SJ et al (2013) Cardiac involvement and treatment-related mortality after non-myeloablative haemopoietic stemcell transplantation with unselected autologous peripheral blood for patients with systemic sclerosis: a retrospective analysis. The Lancet 381(9872): 1116-1124

29. Ferguson EC, Berkowitz EA, Oldham SA (2008) CT imaging of thoracic scleroderma. Contemporary Diagnostic Radiology 31(16):1-5

30. Capobianco J, Grimberg A, Thompson BM et al (2012) Thoracic Manifestations of Collagen Vascular Diseases. Radio Graphics 32(1):33-50

31. Tumsatan P, Wongwiwatchai J, Apinives C et al (2016) Mediastinal lymphadenopathy in patients with systemic sclerosis. J. Med. Assoc. Thai 99(3):348-353 
32. Meune C, Vignaux O, Kahan A et al (2010) Heart involvement in systemic sclerosis: Evolving concept and diagnostic methodologies. Archives of Cardiovascular Diseases 103(1):46-52

33. Leipsic J, Brown J, Pandey A et al (2013) Significance of various pulmonary and extrapulmonary abnormalities on HRCT of the chest in scleroderma lung. Indian Journal of Radiology and Imaging 23(4):304

34. Ooi GC, Mok MY, Tsang KWT et al (2003) Interstitial lung disease in systemic sclerosis: An HRCT-clinical correlative study. Acta Radiologica 44(3):258-264

\section{Publisher's Note}

Springer Nature remains neutral with regard to jurisdictional claims in published maps and institutional affiliations.

Submit your manuscript to a SpringerOpen ${ }^{\circ}$ journal and benefit from:

- Convenient online submission

- Rigorous peer review

- Open access: articles freely available online

High visibility within the field

- Retaining the copyright to your article

Submit your next manuscript at $\boldsymbol{\sim}$ springeropen.com 